\title{
Commercial Photography in the "Eyeball" Economy
}

\author{
Lun Yang \\ Wuhan Textile University School of Media and Communication hubei wuhan \\ 405908259@qq.com
}

Keyword: "Eyeball" Economic; e-Commerce; Commercial photography; Development; Differentiation

\begin{abstract}
In today's "eyeball" the era of economic, commercial photography as a service business to convey advertising messages, graphics, photography, art and photography means to an end. Photography as a medium having a specific binding capacity. Therefore, it is widely used in various fields. It is because of the "eyeball" the rapid development of economy, commerce, commercial photography has become an integral part of, and even played a pillar of strength. Commercial photographers should not only take business photos as their own responsibility, but also need to master a good marketing and planning skills. Make yourself more comprehensive, more extensive and more professional, in this era, go farther!
\end{abstract}

\section{"Eyeball" Economic Era.}

"Eyeball economy" is by attracting public attention to obtain economic benefits of a kind of economic activity, under the push of modern powerful media society, "eyeball economy" are active than any time before. TV needs eyeball, only audience rating can guarantee the economic benefit of TV station; Magazines need eyeballs, and circulation is the economic lifeblood of magazines; The website needs the eyeball more, only the click rate is the centralized embodiment of the website value.

\section{The Development Status of Internet Economy and Commercial Photography in "eyeball" Economy}

The Internet Economy in the "eyeball" Economy. "Eyeball economy" is a special Internet phenomenon. In the Internet, it is often used to check the quality of a website. The competition of the website usually shows how to retain the Internet users, and it is a major problem for a professional website to not go to other similar websites. Many early Internet companies have more opportunities than later ones. At the time when people are fighting for their views and Internet users. They have developed two niche sites with relatively broad markets, one for Internet users and one for experts.

The rapid development of e-commerce, the increasingly fierce competition of the website, quickly catalyzed the sharp change of the website. It is extremely important to have a deeper connotation and more difficult survival and development environment for the website, and how to get people's attention for a long time. The benefits of eyeballs are obvious. The popularity of the website, the content of the website and the location of the website directly affect its benefits.

Commercial Photography in China's "eyeball" Economy. With the rapid development of the Internet and the rapid growth of the Internet economy, China's e-commerce has grown to a certain extent. In previous years, e-commerce was still in its infancy in China. But in recent years, thanks to the rapid development of Internet and logistics, shopping has gained popularity. People gradually realize that online shopping convenience and advantage, but also to recognize the benefits of electronic commerce for small and medium-sized enterprises, thus making more and more enterprises begin to use third-party e-commerce platform. As a result, the e-commerce boom continues.

Now the electronic commerce not only need solid economic, professional management knowledge and high-end customers, need more visualization, such as visual design, interactive 
design, art design and image processing text! These will serve as an important part of the e-commerce terminal! In particular, e-commerce enterprises such as taobao, alibaba, group purchasing and online travel network have become an indispensable and important part of the products. The image of a product directly plays a decisive role in the payment behavior of consumers. Therefore, commercial photography plays a crucial role in this business.

\section{Demand Analysis of Commercial Photography in China's "eyeball" Economy.}

Electronic commerce does not have too much requirement for photography, general SLR and several photoelectric lamps can meet its work requirement. Although the technology difficulty is not high, but in e-commerce photography, it seems, the expression of camera language, mainly in detail the features of the product, performance, connotation, characteristic, what is the need to communicate to consumers the product performance, what are some of the characteristics, the advantage of the products and highlight. Let the consumer of the product's appearance at the same time, also want to combine creativity, make consumers feel they are to enjoy the fun of product let the lens language to communicate to consumers more forward-looking thinking.

The characteristics of e-commerce determine the importance of online marketing and determine the importance of creative products. E-commerce product photography, therefore, need to have a certain atmosphere and narrative situation, resulting in the experience, the details of the product quality consciousness to boost consumer confidence index, make consumers have stronger purchasing desire.

E-commerce is an era of rapid consumption. With professional e-commerce photography, you can quickly and accurately deliver useful information to consumers. Every product can be fully seen and understood by consumers through commercial photography, deepening understanding of the product itself. Therefore, commercial photography is the key to sales.

\section{The Importance of Photography in "eyeball" Economy.}

The photographic image of the "eyeball" economy plays an extremely important role in the whole "eyeball" economic era. The quality of the picture directly determines the product quality, sales and corporate image of enterprises in the "eyeball" economy. Provide rich images, different angles, local amplification function, let customers see more clearly, do lossless scaling processing, let customers fully understand the product and the feel of your online store seriousness, starting from the product display seriously just may have serious sales and after-sales service.

Under the "eyeball" economy, the network sales system in the Internet economy, all kinds of high definition and high-quality pictures will bring consumers closer to the real feeling of shopping. Although shopping consumers in the real world can use direct contact with real objects, try it on. But it will take more time and more price.

Although the consumer is on the network shopping, can only see the picture, can not touch the object, compared to the physical store shopping, there will be a little regret in the user experience. But the network shopping is convenient and fast, saving time and effort, and the cheap price is enough to make up for the missing entity experience.

I make consumers believe that a network marketing platform, cheap and fine is a large proportion of the factors is the platform show us is better, and the picture conveys to consumers the information they want. Therefore, the display of good pictures can give consumers a picture of the perfect experience, which is the respect for consumers, and consumers will believe that you are good.

\section{Concluding Words}

Electronic commerce is like a prosperous, rich golden soil, commercial photography is more like a good hoe, the two inseparable, mutually complementary. The quality of commercial photography directly influences its network marketing and promotion. In the vigorous vitality of e-commerce, 
traditional commercial photography has begun a new stage and new development direction. Image how to meet the requirements of e-commerce, how to promote the healthy development of e-commerce, will gradually become a new target of commercial photography, is also a commercial photographer brand-new development direction and goal.depictions. The abstraction of the female body is a strong case. One of the main reasons why modern women are so obsessed with selfies is that they are amazed at the power of photography to reveal themselves both physically and mentally. They pursue is not, of course, similar to the approval by the authority of "like a man" of photography, but is a kind of brand-new photography, together with the methodology and value standard, also include the recovery in the past were snubbed form "of femininity".

\section{References}

[1] Suzhigang, "China's photographic history", China wenlian publishing house, February 1, 2009.

[2] Gu zheng, history of world photography, zhejiang photography press, July 1, 2006.

[3] Moyuan, market realization - commercial photography, chongqing university press, February 1, 2011.

[4] Sun jixun, "business photography runs out", Harper Collins UK, January 1, 2012.

[5] Jinglin bo, liang chunxiao, "China e-commerce service development report no.1", social science literature publishing house, August 1, 2011.

[6] (British) gref, shopping psychology, citic press, August 1, 2011.

[7] Xie quan, "the cultural connotation of photographic works", journal of xi 'an university of arts and sciences: social science edition, 2008, 2.

[8] Jin tao, a brief analysis of the development of e-commerce in China, management and technology of small and medium-sized enterprises, 2011.

[9] Cao ping, research on the application of business intelligence in e-commerce, technology and industry, 5 issues in 2009.

[10] Liu guanmen, research on commercial display art, tianjin university of technology, 2007. 